\title{
A Possible Phytol-cytoprotective Trait through Reactive Species-Induced Oxidative Stress Ebbing Pathway

Md. Torequl Islam ${ }^{1,2,3,4}$, José Victor de Oliveira Santos ${ }^{2}$, José Roberto de Oliveira Ferreira ${ }^{3}$, João Marcelo de Castro e Sousa ${ }^{5}$, Márcia Fernanda Correia Jardim Paz ${ }^{2}$, Ricardo Melo de Carvalho², Ana Maria Oliveira Ferreira da Mata², Leonardo da Rocha Sousa², Rosália Maria Tôrres de Lima1,2, Milena Braga Soares da Silva², Marcus Vinícius Oliveira Barros de Alencar 1,2, Paulo Michel Pinheiro Ferreira1,3,6, Sandra Maria Mendes de Moura Dantas ${ }^{7}$, Ana Amélia de Carvalho Melo-Cavalcante ${ }^{1,2}$

\section{Abstract}

This study aims at investigating a possible pathway of cytotoxicological status of the diterpenoid essential oil, phytol (PYL). For this brine shrimp lethality bioassay (BSLB) and hemolysis (HL) test systems were selected. In the BSLB, PYL either alone or co-treated with ethylenediaminetetraacetic acid (EDTA), potassium di-chromate $\left(\mathrm{K}_{2} \mathrm{Cr}_{2} \mathrm{O}_{7} ; \mathrm{KD}\right)$, copper sulphate ( $\mathrm{CuSO}_{4} .5 \mathrm{H}_{2} \mathrm{O}$; CS) and 6-hydroxy-2,5,7,8-tetramethylchroman-2-carboxylic acid (Trolox, TRO) as membrane lyser, strong oxidizer, oxidizer-cytogenotoxicant and antioxidative-cell-protestant, respectively. The $\mathrm{HL}$ was carried out in rat erythrocytes (RBCs) taking TRO as a standard. In addition, to view a time-dependent cytotoxic activity of PYL, the mortality of the shrimps was counted at 24 and 48 $h$. Results suggest PYL is non-cytotoxic at low $(40-160 \mu \mathrm{M})$ but toxic at high concentration (2-8 $\mathrm{mM})$ to the shrimps and RBCs. An increased cytotoxicity was observed for $24 \mathrm{~h}$ to $48 \mathrm{~h}$ in brine shrimps. In both cases groups co-treated with cytotoxicants/protestant suggest that PYL is cytoprotective in the presence of oxidizer. The cytoprotectivityof PYL may be connected to its antioxidant potential and cytotoxicity for antioxidant-mediated pro-oxidative effects. In conclusion, PYL is cytoprotective at low concentration but toxic at high, activities found, however, may be linked to the radical scavenging pathway.

\section{Introduction}

Phytol (3, 7, 11, 15-tetramethylhexadec-2-en-1-ol, PYL) is the diterpenoid with evident antioxidant, antimicrobial, cytotoxic and weak mutagenic effects [1]. A substance with such type of activities may
1 Northeast Biotechnology Network (RENORBIO), Postgraduate Program in Biotechnology, Federal University of Piauí, ${ }^{*}$.

2 Laboratory of Genetical Toxicology, Postgraduate Program in Pharmaceutical Sciences, Federal University of Piauí, ${ }^{*}$

3 Laboratory of Experimental Cancerology, Postgraduate Program in Pharmaceutical Sciences, Federal University of Piauí, ${ }^{*}$

4 Department of Pharmacy, Southern University Bangladesh, Mehedibag (Chittagong)-4000, Bangladesh.

5 Department of Biological Sciences, Federal University of Piauí, Picos, 64.049-550, Brazil.

6 Department of Biophysics and Physiology, Federal University of Piauí, .

7 Laboratory of Cytogenetics and Mutagenesis. Federal University of Piauí, ${ }^{*}$.

$$
\text { *: Teresina (Piauí)-64.049-550, Brazil. }
$$

\section{Contact information:}

Md. Torequl Islam.

” rbiotufpi.br@gmail.com.

Keywords

Brine Shrimp; Cytotoprotective;

Oxidative Stress; Phytol;

Toxicity 
promote overall health [2]. Frequently, essential oils (EOs) are more antioxidative and cytotoxic rather than genotoxic. The diterpenic EOs are also wellknown for such type of activities. However, they often have no specific cellular targets may be due to their high hydrophobicity leading to readily permeable of the cell membranes [3].

The brine shrimp lethality bioassay (BSLB) is a popular test system for a wide variety of synthetic, semi-synthetic, and natural substances from inorganic and organic origins due to its rapidity, reliability, economy, simplicity, convenience, and applicability $[4,5]$. Arthropods, the live nauplii (shrimps) are the test system in this purpose. Artificially, the shrimp cysts are undergone for the production of nauplii in brine solution. Live naupli of 24-48 h aged are considered for the better susceptible to the test substances. Finally, the percentage lethality is determined by comparing the mean-surviving larvae of tested and control marked samples.

Otherwise, the hemolysis $(\mathrm{HL})$ test system in rat's erythrocytes (RBCs) is also a popular method to assay the antioxidant behavior of a wide variety of substances. It is due to the rapidity, economy, simplicity, convenience and its wider range of applicability [6]. The stability RBCs is greatly affected by a number of exterior/interior factors such as - temperature, type and charges of chemical substances, and so on. In this occasion hydrogen peroxide $\left(\mathrm{H}_{2} \mathrm{O}_{2}\right)$, a strong hydroxyl radical $(\bullet \mathrm{OH})$ inducer is used to produce oxidative stress to the RBCs. The ${ }^{\bullet} \mathrm{OH}$ eventually binds with metal ions randomly distributed in the DNA, thus implicates DNA damage through the single strand break (SSB) [7].

In this paper, we use a number of cytotoxicants, and a marked cytoprotective to determine the possible cytotoxicological behavior of PYL.

\section{Materials}

\section{Reagents and chemicals}

Tween-80 (0.05\%) dissolved in saline solution (0.9\% $\mathrm{NaCl}$ ) served as the vehicle for PYL and TRO, while distilled water (DW) was used as solvent for others. Phytol (PYL), trolox (6-hydroxy-2,5,7,8-tetramethylchroman-2-carboxylic acid; TRO), ethylenediaminetetraacetic acid (EDTA), potassium dichromate $\left(\mathrm{K}_{2} \mathrm{Cr}_{2} \mathrm{O}_{7} ; \mathrm{KD}\right)$, copper sulfate $\left(\mathrm{CuSO}_{4} .5 \mathrm{H}_{2} \mathrm{O} ; \mathrm{CS}\right)$ and all the necessary reagents and chemicals used in this study were obtained from Sigma-Aldrich (St. Louis, MO, USA).

\section{Shrimp cysts}

For Artemia salina preparation, shrimp cysts were purchased from the local market of Teresina, Brazil.

\section{Experimental animals}

The HL inhibition test was performed in eight weekold Wister albino rats (Rattus norvegicus; body weight: 180-220 g) from the Central Animal House of the Federal University of Piaui, Brazil. The animals were allowed free access to food (Purina, Brazil) and water ad libitum and were kept under controlled lighting (12 h dark/light cycles) at $24 \pm 2{ }^{\circ} \mathrm{C}$.

\section{Preparation of test samples}

In BSLB test, PYL, cytotoxicants (EDTA, KD, CS) and antioxidant/cytoprotective (TRO) were prepared in 40, 80 and $160 \mu \mathrm{M}$ in step 1, while in the step 2 it was 2, 4 and $8 \mathrm{mM}$. Step 3 was continued with PYL at 40-160 $\mu \mathrm{M}$ and 2-8 mM concentrations. $\mathrm{HL}$ test was performed with PYL and/or TRO at 40-160 $\mu \mathrm{M}$ and 2-8 $\mathrm{mM}$ concentrations. In all cases, all the lateral co-treatments were considered at $80 \mu \mathrm{M}$.

\section{Methods}

\section{Brine shrimp lethality bioassay (BSLB)}

This a slight modification of the method described by Meyer et al. [4]. Briefly, brine shrimp (Artemia salina) were hatched using shrimp eggs in a beaker $(0.5 \mathrm{~L})$, filled with articifical sea water containing a 50:50 mixture of brine solution (23.0 gm NaCl, $11.0 \mathrm{gm} \mathrm{MgCl} 2.6 \mathrm{H}_{2} \mathrm{O}, 4 \mathrm{gm} \mathrm{Na} \mathrm{SO}_{4}, 1.3$ gm $\mathrm{CaCl}_{2} \cdot 2 \mathrm{H}_{2} \mathrm{O}, 0.7 \mathrm{gm} \mathrm{KCl}$ in $1 \mathrm{~L}$ distilled water 
and adjusted to $\mathrm{pH} 8.5$ using $\left.1 \mathrm{~N} \mathrm{Na}_{2} \mathrm{CO}_{3}\right)$ and mineral water under constant aeration for $48 \mathrm{~h}$ at $27 \pm 3^{\circ} \mathrm{C}$. After hatching, active nauplii free from egg shells was collected from a brighter portion of the hatching chamber and used for the assay. Ten nauplii were drawn through a Pasteur's pipette and placed in each test tube containing $4.5 \mathrm{~mL}$ of the brine solution. In each experiment, $0.5 \mathrm{~mL}$ of the test sample was added and maintained at the same temperature as hatching under the light and surviving larvae were counted.

Step 1. Grouped as: $P Y L^{*}, E D T A^{*}, K^{*}, C S^{*}$, $P Y L^{*}+E D T A ， \quad P Y L^{*}+K D ， \quad P Y L^{*}+C S ， \quad T R O{ }^{*}+K D$, $\mathrm{TRO}^{*}+\mathrm{CS}, \mathrm{KD}{ }^{*}+\mathrm{PYL}+\mathrm{TRO}, \mathrm{CS}^{*}+\mathrm{PYL}+\mathrm{TRO}$ for Gr-I, Gr-II, Gr-III, Gr-IV, Gr-V, Gr-VI, Gr-VII, Gr-VIII, Gr-IX, $\mathrm{Gr}-\mathrm{X}$ and $\mathrm{Gr}-\mathrm{XI}$, respectively. Staric $\left(^{*}\right)$ mark indicates treatment with 40, 80 and $160 \mu \mathrm{M}$; while un-starics for $80 \mu \mathrm{M}$.

Step 2. Grouped as: $P Y L^{*}, P Y L^{*}+E D T A, P Y L^{*}+K D$, $P Y L^{*}+C S, P Y L^{*}+T R O, P Y L^{*}+T R O+K D$ and $P Y L^{*}+$ TRO+CS for Gr-XII, Gr-XIII, Gr-XIV, Gr-XV, Gr-VI, GrXVII and Gr-XVIII respectively. Staric (*) mark indicates treatment with 2, 4 and $8 \mathrm{mM}$; while un-starics for $80 \mu \mathrm{M}$.

Step 3. Gr-I and Gr-XII from the step 1 and 2 were preceded on to the next day.

The mortality of $A$. salina was counted at $24 \mathrm{~h}$ in step 1 and 2; while 24 and 48 h were considered for step 3. Experiments were conducted along with a negative control (vehicle treated, NC), different concentrations of the test substances in a set of three tubes per dose. Along with percentage lethality, the $\mathrm{LC}_{50}$ (concentration causes 50\% mortality) values were obtained from the best-fit line plotted concentration verses percentage lethality.

\section{Hydrogen peroxide $\left(\mathrm{H}_{2} \mathrm{O}_{2}\right)$ inducedhemolysis ( $\mathrm{HL}$ ) test inraterythrocytes (RBCs)}

To test the inhibition of $\mathrm{HL}$ induced by $\mathrm{H}_{2} \mathrm{O}_{2}$, blood was collected from the retro-orbital plexus of anesthetized (sodium pentobarbital $35 \mathrm{mg} / \mathrm{kg}$; intra-peritoneal) Wistar rats, and the RBCs were prepared for $10 \%$ suspension in phosphate buffer solution (PBS) (pH 7.4). Next, $0.15 \mathrm{~mL} \mathrm{H} \mathrm{O}_{2}$ (200 $\mathrm{mM}$ in PBS; $\mathrm{pH} 7.4$ ) and $0.2 \mathrm{~mL}$ of the sample solution was added to $0.5 \mathrm{~mL}$ of the $10 \%$ RBC suspension. The reaction mixture was incubated at $37^{\circ} \mathrm{C}$ for 30 minutes and immediately centrifuged at 2,500 rpm for 3 minutes. Then, $0.2 \mathrm{~mL}$ of the supernatant was mixed with $2.8 \mathrm{~mL}$ PBS (pH 7.4) and the absorbance was measured at $475 \mathrm{~nm}$ [6]. For the NC, $0.2 \mathrm{~mL}$ of the vehicle was added. The percent rate of hemolysis was calculated using the following formula, taking into account that 100\% hemolysis was induced by $\mathrm{H}_{2} \mathrm{O}_{2}$ (blank):

$$
\begin{gathered}
\text { Inhibition of hemolysis }(\%)= \\
{\left[\left(\mathrm{Abs}_{\text {blank-}} \mathrm{Abs}_{\text {sample }}\right) \times 100\right] / \mathrm{Abs}_{\text {blank }}}
\end{gathered}
$$

where, $\mathrm{Abs}_{\text {blank }}$ is the control absorbance with $100 \%$ hemolysis induced by $\mathrm{H}_{2} \mathrm{O}_{2}$ and reactive Abs $_{\text {sample }}$ is the absorbance of aliquots containing various concentrations of the sample being studied.

This experiment was conducted with the groups as - PYL*, TRO* and $P Y L^{*}+$ TRO. Staric $\left(^{*}\right)$ mark indicates treatment with $40-160 \mu \mathrm{M}$ and 2-8 mM; while un-staric for $80 \mu \mathrm{M}$.

\section{Statistics}

Results were expressed as mean \pm standard deviation (SD). In order to determine differences, data were compared by One-way Analysis of Variance (ANOVA) followed by the Newman-Keuls test ( $p$ $<0.05)$

\section{Results}

\section{BSLB test}

Table 1 indicates the step 1 treatment, where groups (Gr-I to Gr-XI) are treated with PYL, membrane destabilizer (EDTA), oxidant (KD), cytogenotoxicant (CS) and cytoprotectant (TRO). Mortality was counted after a $24 \mathrm{~h}$ exposure, indicating PYL (Gr-l) at all 
Table 1. Effect of cytotomodulators and phytol at low concentration in the brine shrimps.

\begin{tabular}{|c|c|c|c|c|}
\hline \multirow{2}{*}{ Treatments } & \multicolumn{3}{|c|}{$\%$ mortality of nauplii } & \multirow{2}{*}{$\mathrm{IC}_{50}\left(\mathrm{Cl}, \mathrm{R}^{2}\right)$} \\
\hline & $40 \mu \mathrm{M}$ & $80 \mu \mathrm{M}$ & $160 \mu \mathrm{M}$ & \\
\hline Gr-l: PYL* & $0.00 \pm 0.00$ & $0.00 \pm 0.00$ & $0.00 \pm 0.00$ & - \\
\hline Gr-II: EDTA* & $0.00 \pm 0.00$ & $0.00 \pm 0.00$ & $3.33 \pm 0.58$ & $104.4(-,-)$ \\
\hline Gr-III: KD* & $13.33 \pm 0.58$ & $23.33 \pm 0.58$ & $26.67 \pm 0.58$ & $40.08 \pm 0.27(28.80-55.79,0.99)$ \\
\hline Gr-IV: CS* & $3.33 \pm 0.58$ & $13.33 \pm 1.15$ & $20.00 \pm 1.00$ & $64.62 \pm 0.51(35.22-118.6,0.99)$ \\
\hline Gr-V: PYL*+EDTA & $0.00 \pm 0.00$ & $3.33 \pm 0.58$ & $6.67 \pm 0.58$ & $80.10 \pm 1.02$ (very wide, 1.00 ) \\
\hline Gr-VI: PYL*+KD & $6.67 \pm 0.58$ & $10.00 \pm 1.00$ & $16.67 \pm 0.58$ & $53.62 \pm 0.99(3.05-943.0,0.89)$ \\
\hline Gr-VII: PYL*+CS & $3.33 \pm 0.58$ & $10.00 \pm 1.00$ & $16.67 \pm 0.58$ & $66.86 \pm 0.79(20.74-215.5,0.98)$ \\
\hline Gr-VIII: TRO*+KD & $3.33 \pm 0.58$ & $6.67 \pm 0.58$ & $13.33 \pm 0.58$ & $70.58 \pm 1.25(6.50-765.9,0.98)$ \\
\hline Gr-IX: TRO*+CS & $3.33 \pm 0.58$ & $6.67 \pm 0.58$ & $16.67 \pm 0.58$ & $82.83 \pm 2.14(7.86-872.8,0.92)$ \\
\hline Gr-X: KD*+PYL+ TRO & $3.33 \pm 0.58$ & $3.33 \pm 0.58$ & $10.00 \pm 1.00$ & $78.08 \pm 2.06(0.51-11986,0.72)$ \\
\hline Gr-XI: CS*+PYL+ TRO & $3.33 \pm 0.58$ & $6.67 \pm 0.58$ & $16.67 \pm 0.58$ & $82.83 \pm 2.14(7.86-872.8,0.92)$ \\
\hline NC (0.5 mL of vehicle) & & $0.00 \pm 0.00$ & & - \\
\hline
\end{tabular}

the tested doses remain non-cytotoxic. EDTA (Gr-II), the membrane destabilizer produces 3.33\% mortality with the $160 \mu \mathrm{M}$ dose. Highest cytotoxicity was observed in the Gr-III, treated with KD. The KD at 40,80 and $160 \mu \mathrm{M}$ exhibited percentage mortality by $13.33 \pm 0.58,23.33 \pm 0.58$ and $26.67 \pm 0.58$, respectively. The group treated with CS (Gr-IV) was also produced cytotoxicity to the brine shrimps. However, the activity was lower than the Gr-III. CS produced highest percentage mortality with the dose $160 \mu \mathrm{M}$ by $20.00 \pm 1.00$. The PYL groups treated with $80 \mu \mathrm{M}$ of EDTA $(\mathrm{Gr}-\mathrm{V}), \mathrm{KD}(\mathrm{Gr}-\mathrm{VI})$ and CS (Gr-VII), percentage mortality increased in the order of $\mathrm{Gr}-\mathrm{VI}>\mathrm{Gr}-\mathrm{VII}>\mathrm{Gr}-\mathrm{V}$, where Gr-V was almost similar to the group treated alone with EDTA (Gr-II). TRO at 40-160 $\mu \mathrm{M}$ when co-treated with $80 \mu \mathrm{M}$ of KD (Gr-VIII) and CS (Gr-IX), Gr-VIII was more active in cytoprotection than the Gr-IX. The KD $(\mathrm{Gr}-\mathrm{X})$ and CS $(\mathrm{Gr}-\mathrm{XI})$ were co-treated with PYL $(80 \mu \mathrm{M})+$ TRO $(80 \mu \mathrm{M})$ in which $\mathrm{Gr}-\mathrm{XI}$ other than $\mathrm{Gr}-\mathrm{X}$ remained unchanged in mortality rate of the naupli when compared to the Gr-VII and Gr-IX.
In the step 2, Gr-XII treated with PYL in 2, 4 and $8 \mathrm{mM}$ exhibited percentage mortality by 10.00 $\pm 1.00,23.33 \pm 0.58$ and $43.33 \pm 1.15$, respectively, at $24 \mathrm{~h}$. with an exception with the dose $8 \mathrm{mM}, \mathrm{PYL}$ in the Gr-XIII co-treated with $80 \mu \mathrm{M}$ of EDTA produced similar mortality rates to the Gr-XII. However, PYL when co-treated with KD $(80 \mu \mathrm{M})(\mathrm{Gr}-\mathrm{XIV})$, it decreased the mortality rates, where percentage mortality was calculated as 6.67 $\pm 0.58,20.00 \pm 1.00$, and $33.33 \pm 0.58$ with the 2, 4 and $8 \mathrm{mM}$ of $P Y L$, respectively. Group XV suggests that PYL (2-8 $\mathrm{mM})$ co-treated with CS $(80 \mu \mathrm{M})$ produces the mortality rates similar (with an exception with dose $4 \mathrm{mM}$ ) to that of the GrXIII, treated with EDTA. PYL co-treated with TRO $(80 \mu \mathrm{M})(\mathrm{Gr}-\mathrm{XVI})$ increased the mortality rates of shrimps at all doses, however; where the highest percentage of mortality was observed at $8 \mathrm{mM}$ by $46.67 \pm 0.58$. Gr-XVII tells the PYL co-treatment with TRO $(80 \mu \mathrm{M})+\mathrm{KD}(80 \mu \mathrm{M})$ in which the mortality was found to be between the Gr-XIV and GrXII. However, PYL when co-treated with TRO (80 
Table 2. Effect of cytotomodulators on high concentration of phytol in the brine shrimps.

\begin{tabular}{|c|c|c|c|c|}
\hline \multirow{2}{*}{ Treatments } & \multicolumn{3}{|c|}{$\%$ mortality of nauplii } & \multirow{2}{*}{$\mathrm{IC}_{50}\left(\mathrm{Cl}, \mathrm{R}^{2}\right)$} \\
\hline & $2 \mathrm{mM}$ & $4 \mathrm{mM}$ & $8 \mathrm{mM}$ & \\
\hline Gr-XII: PYL* & $10.00 \pm 1.00$ & $23.33 \pm 0.58$ & $43.33 \pm 1.15$ & $3.46 \pm 1.07(0.53-22.56,0.95)$ \\
\hline Gr-XIII: PYL*+EDTA & $10.00 \pm 0.00$ & $23.33 \pm 0.58$ & $40.00 \pm 1.00$ & $3.25 \pm 0.89(0.61-17.19,0.96)$ \\
\hline Gr-XIV: PYL*+KD & $6.67 \pm 0.58$ & $20.00 \pm 1.00$ & $33.33 \pm 0.58$ & $3.34 \pm 0.79(1.04-10.78,0.98)$ \\
\hline Gr-XV: $P Y L^{*}+C S$ & $10.00 \pm 1.00$ & $26.67 \pm 0.58$ & $40.00 \pm 1.00$ & $3.01 \pm 0.60(1.11-8.20,0.99)$ \\
\hline Gr-XVI: PYL*+TRO & $16.67 \pm 0.58$ & $33.33 \pm 0.58$ & $46.67 \pm 0.58$ & $3.13 \pm 1.28(0.08-118.6,0.84)$ \\
\hline Gr-XVII: $P Y L^{*}+T R O+K D$ & $13.33 \pm 0.58$ & $30.00 \pm 1.00$ & $36.67 \pm 0.58$ & $2.41 \pm 0.29(1.63-3.56,0.99)$ \\
\hline Gr-XVIII: $P Y L^{*}+T R O+C S$ & $13.33 \pm 0.58$ & $30.00 \pm 1.00$ & $43.33 \pm 0.58$ & $2.79 \pm 0.58(0.93-8.31,0.98)$ \\
\hline NC (0.5 mL of vehicle) & & $0.00 \pm 0.00$ & & - \\
\hline \multicolumn{5}{|c|}{ 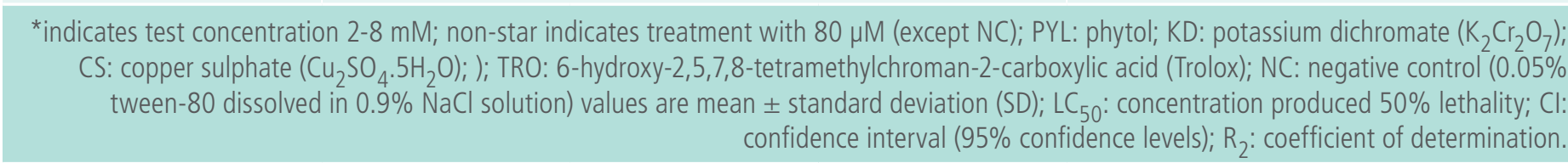 } \\
\hline
\end{tabular}

Table 3. Time and concentration dependent cytotoxicity of phytol in brine shrimps..

\begin{tabular}{|c|c|c|c|c|}
\hline \multirow{2}{*}{ Treatment at hour } & \multicolumn{3}{|c|}{$\%$ mortality of nauplii } & \multirow{2}{*}{$\mathrm{IC}_{50}\left(\mathrm{Cl}, \mathrm{R}^{2}\right)$} \\
\hline & $40 \mu \mathrm{M}$ & $80 \mu \mathrm{M}$ & $160 \mu \mathrm{M}$ & \\
\hline PYL at $24 \mathrm{~h}$ & $0.00 \pm 0.00$ & $0.00 \pm 0.00$ & $0.00 \pm 0.00$ & - \\
\hline \multirow[t]{2}{*}{ PYL at $48 \mathrm{~h}$} & $0.00 \pm 0.00$ & $0.00 \pm 0.00$ & $0.00 \pm 0.00$ & - \\
\hline & $2 \mathrm{mM}$ & $4 \mathrm{mM}$ & $8 \mathrm{mM}$ & \\
\hline PYL at $24 \mathrm{~h}$ & $10.00 \pm 1.00$ & $23.33 \pm 0.58$ & $43.33 \pm 1.15$ & $3.46 \pm 1.07(0.53-22.56,0.95)$ \\
\hline PYL at $48 \mathrm{~h}$ & $13.33 \pm 0.58$ & $30.00 \pm 1.00$ & $46.67 \pm 0.58$ & $2.97 \pm 0.72(0.74-12.01,0.97)$ \\
\hline $\mathrm{NC}(0.5 \mathrm{~mL}$ of vehicle $)$ at $24 \mathrm{~h}$ & & $0.00 \pm 0.00$ & & - \\
\hline $\mathrm{NC}(0.5 \mathrm{~mL}$ of vehicle) at $48 \mathrm{~h}$ & & $0.00 \pm 0.00$ & & - \\
\hline
\end{tabular}

$\mu \mathrm{M})+\mathrm{CS}(80 \mu \mathrm{M})(\mathrm{Gr}-\mathrm{XVIII})$ causes an increase in mortality by 2 and $4 \mathrm{mM}$ concentrations, keeping $8 \mathrm{mM}$ unchanged in comparison to the Gr-XII. An increased mortality rate of Gr-XVIII also observed when compared to the Gr-XV (PYL treated with CS alone) (Table 2).

The data shown in the Table $\mathbf{3}$ are for the step 3, in which Gr-I and Gr-XII were continued with a 24 more to count the mortality of the nauplii. Data suggest, PYL at low concentrations (40-160 $\mu \mathrm{M}$, Gr-I) produces zero (0) mortality to the live nauplii. Otherwise, at 2, 4 and $8 \mathrm{mM}$ of PYL increased the mortality rates by 33.3, 66.7 and $33.4 \%$, respectively.

No mortality of the shrimps was observed in the NC group treated with the vehicle at 24 and $48 \mathrm{~h}$.

\section{HL test}

Data presented in Table 4 indicates that all the treatment groups inhibit lysis of RBCs. In PYL* group the highest inhibition of HL was observed with 160 $\mu \mathrm{M}$ by $58.85 \pm 0.01$, while the lowest with $8 \mathrm{mM}$ by $10.61 \pm 0.01$. The lysis inhibition by the PYL observed ordered by the concentrations as $160 \mu \mathrm{M}>2$ 
Table 4. Oxidative stress-induced erythrocytes lysis assay.

\begin{tabular}{|c|c|c|c|c|c|c|}
\hline \multirow{2}{*}{$\begin{array}{l}\text { Treatment } \\
\text { at hour }\end{array}$} & \multicolumn{3}{|c|}{$\%$ mortality of nauplii } & \multicolumn{3}{|c|}{$\%$ mortality of nauplii } \\
\hline & $40 \mu \mathrm{M}$ & $80 \mu \mathrm{M}$ & $160 \mu \mathrm{M}$ & $2 \mathrm{mM}$ & $4 \mathrm{mM}$ & $8 \mathrm{mM}$ \\
\hline \multirow{2}{*}{$P Y L^{*}$} & $22.91 \pm 0.01^{a}$ & $30.54 \pm 0.01^{a}$ & $58.85 \pm 0.01^{a}$ & $40.41 \pm 0.01^{a}$ & $25.51 \pm 0.01^{a}$ & $10.61 \pm 0.01^{a}$ \\
\hline & \multicolumn{3}{|c|}{ IC 50: $58.74 \pm 1.24(\mathrm{Cl}: 1.27-2709, \mathrm{R} 2: 0.83)$} & \multicolumn{3}{|c|}{ IC50: $5.21 \pm 0.73(\mathrm{Cl}: 1.35-20.07, \mathrm{R} 2: 0.97)$} \\
\hline \multirow{2}{*}{ TRO* } & $32.22 \pm 0.01^{a, b, d}$ & $40.60 \pm 0.01^{a, b}$ & $64.80 \pm 0.01^{a, b}$ & $60.89 \pm 0.01^{a, b, d}$ & $48.04 \pm 0.01^{a, b, d}$ & $21.79 \pm 0.01^{a, b, d}$ \\
\hline & \multicolumn{3}{|c|}{ IC50: $44.37 \pm 1.03$ (Cl: 0.79-2498, R2: 0.83) } & \multicolumn{3}{|c|}{ IC50: $6.49 \pm 0.36(\mathrm{Cl}: 3.73-11.28, \mathrm{R} 2: 0.99)$} \\
\hline \multirow{2}{*}{$P Y L^{*}+T R O$} & $26.26 \pm 0.01^{a, b}$ & $46.93 \pm 0.01^{a, b, c}$ & $69.46 \pm 0.01^{a, b, c}$ & $49.91 \pm 0.01^{a, b}$ & $28.31 \pm 0.01^{a}$ & $15.27 \pm 0.01^{a, b}$ \\
\hline & \multicolumn{3}{|c|}{ IC50: $51.98 \pm 0.72$ (Cl: 9.58-282.1, R2: 0.96) } & \multicolumn{3}{|c|}{ IC50: $5.14 \pm 1.00(\mathrm{Cl}: 0.52-50.83, \mathrm{R} 2: 0.93)$} \\
\hline
\end{tabular}

$\mathrm{mM}>80 \mu \mathrm{M}>4 \mathrm{mM}>40 \mu \mathrm{M}>8 \mathrm{mM}$. Otherwise, TRO* showed lysis inhibition in the order of 160 $\mu \mathrm{M}>2 \mathrm{mM}>4 \mathrm{mM}>80 \mu \mathrm{M}>40 \mu \mathrm{M}>8 \mathrm{mM}$. PYL, when co-treated with TRO $(80 \mu \mathrm{M})$ it, exhibited highest percentage inhibition of HL with 160 $\mu \mathrm{M}$ by $69.46 \pm 0.01$ then followed by $49.91 \pm 0.01$, $46.93 \pm 0.01,28.31 \pm 0.01,26.26 \pm 0.01$ and 15.27 \pm 0.01 with $2 \mathrm{mM}, 80 \mu \mathrm{M}, 4 \mathrm{mM}, 40 \mu \mathrm{M}$ and 8 $\mathrm{mM}$, respectively.

\section{Discussion}

The BSLB is extensively used test system in the primary concerning in the toxicity assessment of crude as well as isolated compounds in brine shrimps. Furthermore, the cytotoxic compounds having significant sensitivity towards the shrimps, this assay can be recommended as a guide for the detection of antitumor and pesticidal compounds [4]. In addition, this bioassay has a great correlation to the human solid tumor cell lines. Specifically, BSLB acts through the inhibition in the embryonic development stages as the agents tested in this system are considered to have ovicidal and larvicidal properties [8]. Mainly, the mortality of the larvae in BSLB relates to- a) detergent/destabilization activity of the test substances which may cause lysis/ protrusion of the cell membrane, b) overproduction of reac- tive oxygen/nitrogen species (ROS/RNS) leading to the oxidative damage and/or prooxidative effects; causing destruction of the genetic materials such as proteins, lipids and DNA, and RNA other related phenomena. It is to be mentioned that those are the main causes of cyto-/genotoxic damage of the eukaryotic cells.

In this study, we firsty performed a cytotoxicological study of PYL in BSLB. In addition, for further clarification, we carried out $\mathrm{HL}$ analysis, which is a well-known ${ }^{\bullet} \mathrm{OH}$-induced hemolysis test system for substances with antiradical capabilities. Although, PYL is evident for its antimicrobial and cytotoxic activities [1] but the possible action mechanisms are yet to be found out. After going through this broad viewpoint, we carried out a three-step study, which was further divided into a number of treatment groups at different concentrations.

In the step 1 (data shown in Table 1), PYL (GrI) at low concentrations (40-160 $\mu \mathrm{M})$ produced no mortality to the brine shrimps. In Gr-II, EDTA exhibited poor mortality only at the highest treated dose $(160 \mu \mathrm{M})$, while in $\mathrm{Gr}-\mathrm{V}$ with 80 and $160 \mu \mathrm{M}$. The EDTA mainly acts through membrane destabilization by fluidization and expansion effects. The intercalation of EDTA into the lipid membrane induces membrane curvature. Further loss of material from the lipid membrane facilitates membrane instability, 
leading to membrane permeabilization and cell lysis [9]. Although the EDTA action on live nauplii was insignificant, but PYL at $80 \mu \mathrm{M}$, co-treated with EDTA did not inhibit the event. PYL may have no antagonistic interaction with EDTA. Furthermore, insignificant increased in mortality rates may be due to non-toxic effects of PYL at $80 \mu \mathrm{M}$ as the membrane potential (MP) is an important parameter for illustrating the mechanism of action of cytotoxic molecules. Treatments that alter the MP can also change cellular functions. There are agents that may cause the MP to approach or become zero, such as carbonyl cyanidem-chlorophenylhydrazone [10], with the ultimate result being the loss of cellular materials, irregular cellular metabolism, and finally cell death. EDTA, other than PYL may act through this pathway.

Chromium (VI) compounds have been reported to be toxic and carcinogenic as it can readily pass through the cell membranes. Once inside the cell, $\mathrm{Cr}(\mathrm{VI})$ is reduced to its lower oxidation states $[\mathrm{Cr}$ (V)] and [Cr (IV)] and then $\mathrm{Cr}$ (III) by low molecular weight molecules, enzymatic and non-enzymatic reductants. These reactive chromium intermediates are capable of generating a whole spectrum of ROS; in excess of those can cause injury to cellular proteins, lipids and DNA lead to a state known as oxidative stress [11]. In a recent study, Rasool et al. [12] suggests that KD produces high malondialdehyde (MDA) and low levels of antioxidant enzymes [catalase (CAT), superoxide dismutase (SOD) and glutathione peroxidase (GPx)] in male Swiss mice, leading to DNA damage in testicular cells, thus the adverse reproductive abnormalities in animals. Otherwise, ROS coming from the substances may implicate DNA damage; one of them is the ${ }^{\bullet} \mathrm{OH}$ which eventually binds with metal ions randomly distributes in the DNA; the ultimate result is the single strand break (SSB) [7], whichever also evident for oxidative DNA modification [13]. Pejin et al. [14] suggested that PYL is a potent radical scavenger, which potentially scavenged $\bullet \mathrm{OH}$, superoxide anion $\left({ }^{\bullet} \mathrm{O}_{2}^{-}\right)$, methoxy $\left({ }^{\bullet} \mathrm{CH}_{2} \mathrm{OH}\right)$, carbon-dioxide anion $\left({ }^{\bullet} \mathrm{CO}_{2}^{-}\right)$, nitric-oxide (NO$\left.{ }^{\bullet}\right)$ and 2,2-diphenyl1-picrylhydrazyl (DPPH) radicals. In our study, Gr-III treated with KD exhibits higher mortality rates at all tested concentrations. However, KD in Gr-VI, Gr-VIII and Gr-X when co-treated with PYL $(80 \mu \mathrm{M})$, TRO $(80 \mu \mathrm{M})$ and PYL $(80 \mu \mathrm{M})+\mathrm{TRO}(80 \mu \mathrm{M})$ reduced the mortality rates to the shrimps. The observed activity was more prominent with the order of PYL + TRO $>$ TRO $>$ PYL. TRO is a well-known antioxidant for its reactive oxidisable species capturing capacity. Thus, PYL and TRO may protect the nauplii through the pathway above mentioned.

It is noteworthy that the formation of ROS in biological systems can be accomplished by copper(II) $\left(\mathrm{Cu}^{2+}\right)$ catalysis, with the consequent cytotoxic response [15]. The genotoxicity of CS in Allium cepa root cells in a mild alkaline comet assay (pH 12.3), is evident for the single strand breaks DNA [16]. Cu (II) is also an inflammatory mediator to the cells [17].A study conducted with copper oxide nanoparticles (CUONPs) and CS in the arthropod, Drosophila indicates that both CuONPs and CS are genotoxic. There is a suggestion for oxidative stress- mediated damage to the cell macromolecules [18]. In our study, by considering Gr-V, VII, IX and XI, it should be said that CS has toxic effects inthe brine shrimps. Although, there is a reduced mortality rate observed in the Gr-VII, Gr-IX and Gr-XI co-treated with PYL $(80 \mu \mathrm{M})$, TRO $(80 \mu \mathrm{M})$ and PYL $(80 \mu \mathrm{M})+$ TRO $(80 \mu \mathrm{M})$ but the activity was almost similar except 40 and $80 \mu \mathrm{M}$ doses treated with $80 \mu \mathrm{M}$ PYL in the Gr-VII. Thus, the activities of both PYL and TRO may be more concerned with the neutralization of strong oxidizer, KD-mediated oxidizing effects.

In the step 2 (data shown in Table 2), high concentrations of PYL alone as well as co-treatments exhibited a dose-dependent cytotoxicity. In comparison to Gr-XII (PYL), Gr-XIII (PYL+EDTA), GrXIV (PYL+KD), Gr-XV (PYL+CS) and Gr-XVII (PYL+ TRO+KD) decreased the mortality rates of the brine shrimps. The decreased order of the mortality rate was Gr-XIV> Gr-XVII>Gr-XIII>Gr-XV. Otherwise, PYL co-treated with $80 \mu \mathrm{M}$ of TRO (Gr-XVI) exhi- 
bited an increased percentage of mortality of the shrimps. The similar event was observed in case of Gr-XVIII; where PYL at $2 \mathrm{mM}$ and $4 \mathrm{mM}$ exhibited increased mortality rates remaining unchanged with $8 \mathrm{mM}$ in comparison to the Gr-XII. The terpenoid EOs are the good examples of antioxidants. At low doses, this kind of EOs can act ascellular protectants as they scavenge reactive species harmful to the cell membrane. But EOs are hydrophpobic in nature, which at high concentrations capable to cross the cell as well as mitochondrial membranes and may destroy the cellular essential molecules and genetic materials [3]. It may be due to the fact that at low concentration there is a balance between the oxidative species and antioxidant molecules; but at high concentration oxidative radicals may contribute an obstacle to the molecules to be available to interact and cross the cell membranes. In addition, it may cause an increased in membrane permeability to external toxicants and internal cellular essentials. Bakkali et al. [3] suggested that in eukaryotic cells, EOs can provoke depolarization of the mitochondrial membranes by decreasing the membrane potential. This affects ionic $\mathrm{Ca}^{++}$cycling and other ion channels, eventually reducing the $\mathrm{pH}$ gradient, affecting the proton pump and the ATP pool, and changing the fluidity of membranes. The latter effect causes the membranes to become abnormally permeable, resulting in leakage of radicals, cytochrome $\mathrm{C}, \mathrm{Ca}^{++}$, and proteins, thus resulting in oxidative stress and bioenergetic failure. Permeabilization of outer and inner mitochondrial membranes leads to cell death by apoptosis and necrosis. Antioxidant-mediated this type of activity is called the prooxidative (protective) activity. As GrXIII and Gr-XV were treated with the oxidant, KD; the reduced mortality of the shrimps may be due to both antioxidant and prooxidant capabilities of PYL. Furthermore, results from the Gr-XIV are the confirmation about the PYL-mediated prooxidative effect at high concentrations.

However, by considering the Gr-IV and Gr-XI we can say that CS produces toxic effects on the brine shrimps, which may relate to its oxidative stressmediated cytogenotoxicity. According to Lo'pezCamarillo et al. [19], eukaryotic double strand breaks (DSBs) can be repaired by homologous recombination repair (HRR) and nonhomologous end-joining (NHEJ). Thus the groups (Gr-VII, Gr-IX, Gr-XI and Gr-XV) co-treated with PYL and/or TRO may protect the shrimp cells from oxidative stress-mediated this type of detrimental effect.

However, the cytotoxic activities of EOs or their major components are sometimes activated by light. There, they may act through adduct formation. The phototoxic EOs are capable of crossing the cell membrane without causing damage to it or to the cellular macromolecules, therefore reactions forming radicals inside the cell upon exposure to light may be occurring. However, phototoxicity of EOs is dependent on the type of compounds present in EOs, concentration and their localization in the cell, as well as whether or not they produce different types of radical upon exposure to light [3]. According to Ghaneian et al. [20] PYL produced time dependent toxicity in albino mice. It is wellknownthat BSLB is a light-dependent test system as for continuous light and temperature maintenance is essentialalong with electrolyte balance and $\mathrm{pH}$ for the livelihood of the shrimps. In this study, the Gr-I and Gr-XII in the step 3 (Table 3) confirming that PYL at higher rather than low concentrations is cytotoxic; and the toxicity depends on the time of exposure of this diterpenic EO. Thus, our findings may link to the cytotoxic activity observed in Schistosoma mansoni by Moraes et al. [21] and Ghaneian et al. [20]. However, exposure to EOs could induce mitochondrial and DNA damage due to the formation of respiratory deficient cytoplasmic petite mutants, in which exponentially growing cells are more sensitive to [3]. PYL, in this occasion may also produce death to the shrimps by this way.

Otherwise, PYL at $80 \mu \mathrm{M}$ as a co-treatment with the Gr-VI, Gr-VII, Gr-X and Gr-XI other than alone reduced the percentage of mortality of the shrimps; whichever also seen in the Gr-XIV and Gr-XVII co- 
Figure 1: Postulated toxicological events of phytol.

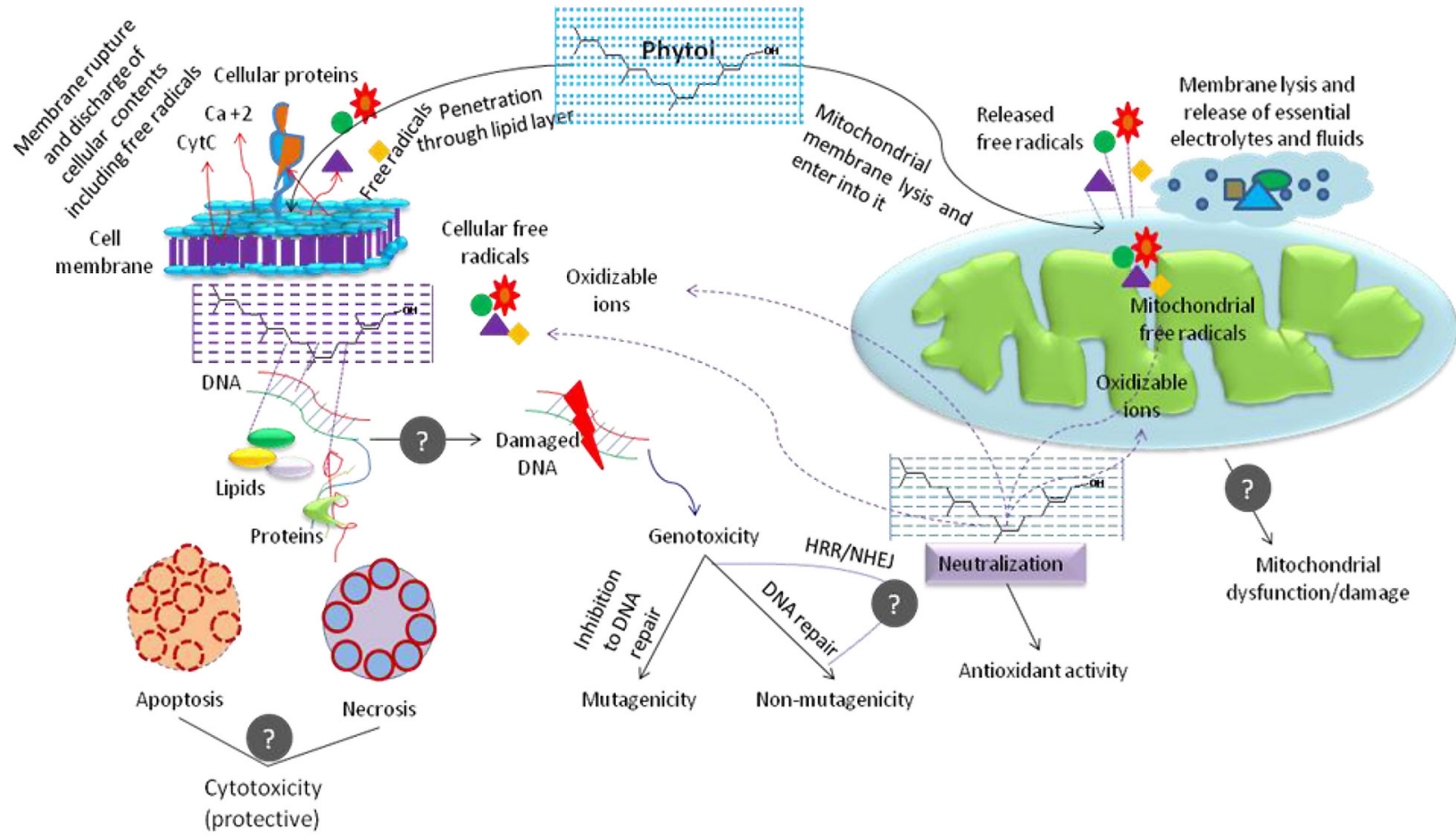

PYL at low concentration: acting as a radical scavenger and protecting cell from oxidative stress-induced detrimental effects, thus the antioxidant activity. PYL at high concentration: due to high hydrophobicity, readily crossing the cellular as well as mitochondrial membranes, causing loss of cellular essentials with the permission to the exterior toxicants, changing membrane potential, neutralizing reactive species and eventually causing self-destruction to the cell macromolecules such as - proteins, lipids and DNA; thus leading cyto-/genotoxicity and mitochondrial dysfunction. Genotoxic damage, if remains un-repaired it may turn to mutagenic event.

treated with $\mathrm{KD}(80 \mu \mathrm{M})$ and TRO $(80 \mu \mathrm{M})+\mathrm{KD}(80$ $\mu \mathrm{M})$, respectively.

PYL has a hydroxyl (-OH) group at its $\mathrm{C} 1$ position. According to the Gyawali and Ibrahim [22] substances having active $-\mathrm{OH}$ group with antioxidative potential may cause cytotoxicity. Terpenoid EOs are the best examples in this occasion [3]. Hydrogen peroxide $\left(\mathrm{H}_{2} \mathrm{O}_{2}\right)$ is a well-known strong oxidizer as it potentially produces $\bullet \mathrm{OH}$, which is causing stress to the RBCs in HL assay [6]. Our finding suggests PYL to have significant $(p<0.05)^{\bullet} \mathrm{OH}$ scavenger up to $4 \mathrm{mM}$. Although, the observed activity was lower than the TRO treated with similar concentrations, but PYL when co-treated with TRO $(80 \mu \mathrm{M})$; it significantly increased the percentage inhibition of $\mathrm{HL}$ with all the test concentrations in comparison to the $\mathrm{NC}$ and $\mathrm{PYL}^{*}$ groups. Interestingly, PYL in addition to TRO $(80 \mu \mathrm{M})$ at 2-8 $\mathrm{mM}$ concentrations produces inhibition rate within the $P Y L^{*}$ and $T R O^{*}$ groups. By considering the $\mathrm{HL}$ inhibition, the treatments with
$40 \mu \mathrm{M}$ we can say that PYL at very low concentration is incapable to combat potential of the ${ }^{\bullet} \mathrm{OH}$ coming from the $\mathrm{H}_{2} \mathrm{O}_{2}$; thus the diminishing the protection of RBCs from oxidative stress-mediated lysis. However, PYL at high concentrations (4 mM and $8 \mathrm{mM}$ ) also reduces the protectivity, this may relate to the high concentration-mediated membrane lysis and cytotoxicity observed in brine shrimps.

Finally, by considering Gr-VI to Gr-IX, Gr-X, GrXI, Gr-XVI to Gr-XVIII in BSLB test and all the test groups shown in $\mathrm{HL}$ assay we can tell that PYL produced TRO-like activity. According to the above findings a PYL-mediated cyto-events has been shown in Figure 1.

\section{Conclusion}

PYL induced cytotoxicity on brine shrimps especially at higher concentrations andinhibited $\mathrm{HL}$ in low as well as high concentrations. The activity found in 
low concentration may be due to its cytotoxic effect of it seems capability, which may relate to its radical scavenging power and the cytoxicity due to antioxidant-mediated prooxidative effects. Cytoprotectivity of PYL is concentration-dependent while the cytoxicityseems to be concentration and time-dependent.

\section{Abbreviations}

BSLB: brine shrimp lethality bioassay; CAT: catalase; - $\mathrm{CH}_{2} \mathrm{OH}$ : methoxy radical; ${ }^{\bullet} \mathrm{CO}_{2}$-: carbon-dioxide anion radical; CS: copper sulphate $\left(\mathrm{CuSO}_{4} \cdot 5 \mathrm{H}_{2} \mathrm{O}\right)$; CuONPs: copper oxide nanoparticles; $-\mathrm{DPPH}$ : 2,2-diphenyl-1-picrylhydrazyl radical; DW: distilled water; EDTA: ethylenediaminetetraacetic acid; EO: essential oil; GPx: glutathione peroxidase; HL: hemolysis; KD: potassium di-chromate $\left(\mathrm{K}_{2} \mathrm{Cr}_{2} \mathrm{O}_{7}\right)$; $\mathrm{MP}$ : membrane potential; $\mathrm{NO}^{\bullet}$ : nitric-oxide radical; RNS:

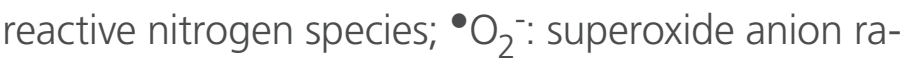
dical; PYL: phytol (3, 7, 11, 15-tetramethylhexadec2-en-1-ol); RBC: red blood corpuscles; ROS: reactive oxygen species; SOD: superoxide dismutase; TRO: trolox (6-hydroxy-2, 5, 7, 8-tetramethylchroman2-carboxylic acid).

\section{Acknowledgement}

The Brazilian agency CAPES in the form of grants (Project \#109/14).

\section{Conflict of interest}

We have no competing interest from any single point of view.

\section{References}

1. M. T. Islam, M.V.O.B. Alencar, K. C. Machado, K.C. Machado, A. A. C. Melo-Cavalcante, D. P. Sousa, R. M. Freitas. Phytol in a pharma-medico-stance. Chemico-Biological Interactions 2015; 240: 60-73.

2. J. M. M. Andrade, D. Fasolo. Polyphenol Antioxidants from Natural Sources and Contribution to Health Promotion. Chapter 20, Polyphenols in Human Health Diseases 2014; 1: 253-265.

3. F. Bakkali, S. Averbeck, D. Averbeck, M. Idaomar. Biological effects of essential oils - A review. Food and Chemical Toxicology
2008; 46: 446-475

4. B. N. Meyer, N. R. Ferrigni, J. E. Putnam, L. B. Jacobson, D. E. Nichols, J. L. McLaughlin. Brine shrimp: a convenient general bioassay for active plant constituents. Planta Medica 1982; 45: 31-34.

5. Y. Baravalia, Y. Vaghasiya, S. Chanda. Brine Shrimp Cytotoxicity, Anti-inflammatory and Analgesic Properties of Woodfordia fruticosa Kurz Flowers. Iranian Journal of Pharmaceutical Research 2012; 11: 851-861.

6. T. K. Girish, P. Vasudevaraju, U. J. S. Prasada Rao. Protection of DNA and erythrocytes from free radical induced oxidative damage by black gram (Vigna mungo L.) husk extract. Food and Chemical Toxicology 2012; 50: 1690-1696.

7. E. Sage, L. Harrison. Clustered DNA lesion repair in eukaryotes: Relevance to mutagenesis and cell Survival. Mutation Research 2011; 711: 123-133.

8. A. Manilal, S. Sujith, K. G. Seghal, J. Selvin, C. Shakir. Cytotoxic potentials of red alga, laurenciabrandenii collected from the Indian coast. Global Journal of Pharmacology 2009; 3: 90-94.

9. V. Prachayasittikul, C. Isarankura-Na-Ayudhya, T. Tantimongcolwat, C. Nantasenamat, H. J. Galla. EDTA-induced membrane fluidization and destabilization: biophysical studies on artificial lipid membranes. Acta Biochimica e Biophysica Sin (Shanghai) 2007; 39: 901-913.

10. Y. Zhang, X. Liu, Y. Wang. Antibacterial activity and mechanism of cinnamon essential oil against Escherichia coli and Staphylococcus aureus. Food Control 2016; 59: 282-289.

11. A. K. Patlolla, C. Barnes, D. Hackett, P. B. Tchounwou. Potassium dichromate induced cytotoxicity, genotoxicity and oxidative stress in human liver carcinoma (HepG2) cells. International Journal of Environmental Research, Public Health 2009; 9: 63653.

12. M. Rasool, K. Zaigham, A. Malik, M. I. Naseer, A. Umm-EHabiba, A. Manan, M. H. Qazi, M. Asif. Potential reproductive health effects and oxidative stress associated with exposure to potassium dichromate $\left(\mathrm{K}_{2} \mathrm{Cr}_{2} \mathrm{O}_{7}\right)$ and magnesium sulphate $\left(\mathrm{MgSO}_{4}\right)$ in male mice. Pakistan Journal of Medical Sciiences 2014; 30: 819-823.

13. R. Rucinska, R. Sobkowiak, E. A. Gwozdz. Genotoxicity of lead in lupin root cells as evaluated by the comet assay. Cellular and Molecular Biology Letters 2004; 9: 519-528.

14. B. Pejin, A. Savic, M. Sokovic, J. Glamoclija, A. Ciric, M. Nikolic, K. Radotic, M. Mojovic. Further in vitro evaluation of antiradical and antimicrobial activities of phytol. Natural Product Research 2014; 28: 372-376. 
15. J. Sans, A. M. Aguilera, P. Faundez, P. Troncoso, V. Fernandez, L. A. Videla. Influence of copper-(II) on colloidal carbon-induced Kupffer cell-dependent oxygen uptake in rat liver: relation to hepatotoxicity. Free Radical Research 1999; 30: 489-498.

16. M. Yildiz, I. H. Ciğerci, M. Konuk, A. F. Fidan, H. Terzi. Determination of genotoxic effects of copper sulphate and cobalt chloride in Allium cepa root cells by chromosome aberration and comet assays. Hemosphere 2009; 75: 934-938.

17. G. D. Clayton, F. E. Clayton. Patty's industrial hygiene and toxicology. Third edition. Vol. 2, Part 6 Toxicology. NY: John Wiley and Sons,1981. ISBN 0-471-01280-7.

18. E. R. Carmona, C. Inostroza-Blancheteau, V. Obando, L. Rubio, R. Marcos. Genotoxicity of copper oxide nanoparticles in Drosophila melanogaster. Mutation Research - Genetic Toxicology and Environmental Mutagenesis 2015; 791: 1-11.

19. C. Lo'pez-Camarillo, M. Lopez-Casamichana, C. Weber, N. Guillen, E. Orozco, L. A. Marchat. DNA repair mechanisms in eukaryotes: Special focus in Entamoeba histolytica and related protozoan parasites. Infection, Genetics and Evolution 2009; 9: 1051-1056.

20. M. T. Ghaneian, M. H. Ehrampoush, A. Jebali, S. Hekmatimoghaddam, M. Mahmoudi. Antimicrobial activity, toxicity and stability of phytol as a novel surface disinfectant. Environmental Health Engneering and Management Journal 2015; 2: 13-16.

21. J. Moraes, R. N. Oliveira, J. P. Costa, A. L. G. Junior, D. P. Sousa, R. M. Freitas, S. M. Allegretti, P. L. S. Pinto. Phytol, a Diterpene Alcohol from Chlorophyll, as a Drug against Neglected Tropical Disease Schistosomiasis mansoni. PLOS Neglected Tropical Diseases 2014; 8: e2617.

22. R. Gyawali, S. A. Ibrahim. Natural products as antimicrobial agents. Food Control 2014; 46: 412-429.
Publish in International Archives of Medicine

International Archives of Medicine is an open access journal publishing articles encompassing all aspects of medical science and clinical practice. IAM is considered a megajournal with independent sections on all areas of medicine. IAM is a really international journal with authors and board members from all around the world. The journal is widely indexed and classified Q1 in category Medicine. 